10 Blum RW, Garell D, Hodgman CH, Jorissen TW, Okinow NA, Orr DP, et al. Transition from child-centered to adult health-care systems for adolescents with chronic conditions: a position paper for the Society of Adolescent Medicine. J Adolesc Health 1993; 14: 570-6.

11 McDonagh JE, Kelly DA. Transiting care of the pediatric recipient to adult care givers. Pediatr Clin North Am 2003; 50: 1561-83.

12 Royal College of Nursing. Adolescent Transition Care. RCN Publications, 2004

13 Vostanis P. Patients as parents and young people approaching adulthood: how should we manage the interface between mental health services for young people and adults? Curr Opin Psychiatry 2005; 18: 449-54.

14 Commission for Health Improvement. Transition of Care between CAMHS and Adult Services. Commission for Health Improvement, 2003 (http:// www.chi.nhs.uk/Ratings/Trust/Indicator/indicatorDescriptionshort. asp? indicatorld=3555).

15 Department of Health. Getting the Right Start: National Service Framework for Children: Emerging Findings. Department of Health, 2003.

16 Department for Education and Skills. Every Child Matters: Change for Children. Department for Education and Skills, 2004.

17 Department of Health and Department for Education and Skills. National Service Framework for Children, Young People and Maternity Services. Department of Health, 2004.

18 Singh SP, Paul M, Ford T, Kramer T, Weaver T. Transitions of care from child and adolescent mental health services to adult mental health services (TRACK study): a study of protocols in Greater London. BMC Health Serv Res 2008; 8: 1-7.

19 Freeman G, Crawford M, Weaver T, Low J, de Jonge F. Promoting Continuity of Care for People with Severe Mental IIIness whose needs span Primary, Secondary and Social Care: A Multi-Method Investigation of Relevant Mechanisms and Contexts. NCCSDO, 2002.

20 Ritchie J, Spencer L. Qualitative data analysis for applied policy research. In Analysing Qualitative Data (eds A Bryman, R Burgess): 172-94. Routledge 1994
21 Patel V, Flisher AJ, Hetrick S, McGorry P. Mental health of young people: a global public-health challenge. Lancet 2007; 369: 1302-13.

22 McGorry P. The specialist youth mental health model: strengthening the weakest link in the public mental health system. Med J Aust (suppl) 2007; 187: s53-6.

23 Cosgrave EM, Yung AR, Killackey E, Buckby JA, Godfrey, KA, Standford CA, et al. Met and unmet need in youth mental health. J Ment Health 2008; 17 618-28

24 Davis M, Geller JL, Hunt B. Within-state availability of transition-to-adulthood services for youths with serious mental health conditions. Psychiatr Serv 2006; 57: 1594-9.

25 Singh SP, Evans N, Sireling, L, Stuart H. Mind the gap: the interface between child and adult mental health services. Psychiatr Bull 2005 29: 292-4.

26 Burns T, Clement S, Cathy J, McLaren S, Rees-Jones, I, Wykes T, et al. Experiences of Continuity of Care and Health and Social Outcomes: The ECHO Study. National Coordinating Centre for Service Delivery and Organisation, 2007.

27 National CAMHS Review. Children and Young People in Mind: the Final Report of the National CAMHS Review. Department for Children, Schools and Families and Department of Health, 2008.

28 Department for Education and Skills and Department of Health. Report on the Implementation of Standard 9 of the National Service Framework for Children, Young People and Maternity Services. Department of Health, 2006.

29 Maitra B, Jolley A. Liaison between child and adult psychiatric services. In Family Matters: Interface Between Child and Adult Mental Health (eds P Reder, M McClure, A Jolley): 285-302. Routledge, 2000.

30 Health and Social Care Advisory Service. CAMHS to Adult Transition: $A$ Literature Review for Informed Practice. Health and Social Care Advisory Service (HASCAS) Tools for Transition. Department of Health and HASCAS 2006 (http://www.hascas.org.uk/pdf files/HASCAS\%20tools\%20for\%20 transition\%20Lit\%20Review.pdf).

31 Social Exclusion Unit. Transitions: Young Adults withComplex Needs. Office of the Deputy Prime Minister, 2005.

\title{
Edvard Munch (1863-1944)
}

\author{
Alexandra Pitman
}

The Norwegian Expressionist Edvard Munch caused outrage when his paintings were first shown in Berlin but became one of the most prolific artists of his time. Often described as having had bipolar affective disorder, his low moods and sense of isolation are evident in works such as The Scream, Separation, and Evening on Karl Johan. Yet the evidence of his diaries and his many biographies suggest more plausible diagnoses of depressive disorder and comorbid alcohol dependence. Art historians acknowledge his ability to represent extreme emotional states, while debating the extent to which Munch exploited the market for his 'flawed personality'. 